\title{
Cardiovascular Morbidity among Medical Staff in the Russian Subarctic Territory
}

\author{
T. A. Ermolina ${ }^{1}$; N. A. Martynova ${ }^{2}$; A. G. Kalinin ${ }^{2}$; R. V. Kubasov, PhD ${ }^{2 *}$; \\ E. D. Kubasova ${ }^{2}$ \\ ${ }^{I}$ Northern (Arctic) Federal University named after M.V. Lomonosov \\ ${ }^{2}$ Northern State Medical University \\ Archangelsk, the Russian Federation
}

\begin{abstract}
The aim of our study was to assess the level of cardiovascular disease among medical personnel working in extreme Arctic climatogeographic conditions.

Materials and Methods: We used the materials from periodic preventive medical examinations to study the state of health of 3,013 people working in medical organizations. All patients were between 20 and 64 years of age (mean of $38.4 \pm 0.71$ years). Using a questionnaire, we conducted a survey on the person's attitude toward the state of health and the quality of life with respect to cardiovascular disorders.

Results: The total morbidity of the medical workers was higher than the average for the entire population of the Arkhangelsk region and the Russian Federation as a whole. Cardiovascular diseases (CVD) occupied about a third of the total structure of chronic pathology among medical workers in the Northern territories. Among CVD, the most frequently registered ailments were arterial hypertension, coronary heart disease, and venous lesions of the lower extremities. According to the results of the survey to assess the level of health in relation to the cardiovascular system, more than half of the surveyed physicians regarded it as satisfactory. At the same time, about one-third of the respondents rated their health level as excellent or good.

Conclusion: the work of medical workers, especially in extreme climatogeographic Northern conditions, can be considered as an additional risk factor for chronic diseases. The identified adverse trends in the deterioration of the medical workers' health dictate the need for the organization and implementation of preventive measures aimed at the early detection of CVD, followed by medical and recreational activities. (International Journal of Biomedicine. 2019;9(2):185-186.)
\end{abstract}

Key Words: medical workers $\bullet$ morbidity $\bullet$ cardiovascular disease $\bullet$ Arctic territories

\section{Introduction}

Living in the Arctic territories of Russia is uncomfortable because of the severe weather conditions, such as temperature and wind characteristics, sudden changes in atmospheric pressure, pronounced magnetic disturbances, and specific photoperiodicity. ${ }^{(1)}$ In addition, there are environmental problems associated with man-made environmental pollution. ${ }^{2}$

The morbidity of the population of the North of Russia is much higher than the average rate in the Russian Federation. The most common health problems are diseases of the cardiovascular and endocrine systems, and cancer pathology. ${ }^{(3)}$

*Corresponding author: Roman V. Kubasov, PhD. Northern State Medical University.Archangelsk,Russia.E-mail:romanas2001@, gmail.com
Labor activity of medical workers in this region is said to be one of the most intensive. ${ }^{(4,5)}$ Significantly increased over the past decade, the professional burden, along with the deterioration of the socio-economic situation, can have a negative impact on the health of these workers up to permanent disability. ${ }^{(6,7)}$

The aim of our study was to assess the level of cardiovascular disease among medical personnel working in extreme Arctic climatogeographic conditions. The results can serve to justify developing measures to prevent cardiovascular disorders and reduce their consequences in order to increase professional longevity and life expectancy.

\section{Materials and Methods}

The bases for the study were medical organizations operating in the Arctic territory of the Arkhangelsk region (Arkhangelsk, 
Severodvinsk, Novodvinsk, and Primorsky district).

We used the materials from periodic preventive medical examinations to study the state of health of 3,013 people working in medical organizations: 796 doctors, 2,217 employees of secondary medical personnel. All patients were between 20 and 64 years of age (mean of $38.4 \pm 0.71$ years). Using a questionnaire, we conducted a survey on the person's attitude toward the state of health and the quality of life with respect to cardiovascular disorders. ${ }^{(8)}$ The questionnaire included the following blocks of topics: marital status, working conditions, health status, and presence of chronic and occupational diseases. Based on the results of the responses, a number of indicators were formed (current self-assessment of health level, dynamic self-assessment of health level, level of medical activity), characterizing the nature of life and activity and its relation to possible diseases.

\section{Results and Discussion}

The total morbidity of the medical workers we examined was 1990.4 per 1000 persons. The result was higher than the average for the entire population of the Arkhangelsk region and the Russian Federation as a whole (1901.0 and 1583.2 cases per 1000 population, respectively).

Among all the examined persons, 47.5\% had chronic diseases. The most common among chronic diseases were various nosological forms of the cardiovascular system - more than $30 \%$. In the structure of cardiovascular diseases, the most frequent were arterial hypertension (67\%), coronary heart disease (CHD) (13\%), and venous lesions of the lower extremities (7\%).

Pathology of the circulatory system among health workers under the age of 30 years was detected in $10.2 \%$ of those surveyed; among those over 40 years - in $24.3 \%$, with $20 \%$ of persons having two forms of this class of diseases. The average age of persons without cardiovascular disease was $25.1 \pm 0.8$ years, with one nosological form $-35.4 \pm 0.3$ years, and with two diseases $-42.3 \pm 2.5$ years.

The distribution of the incidence of cardiovascular diseases (CVD), depending on the length of professional service, revealed that the average length of service of persons without diseases was $4.2 \pm 1.1$ years, with one nosological form $-12.0 \pm 1.3$ years, with two $-18.2 \pm 2.5$ years. With work experience in the specialty up to 5 years, $11.6 \%$ of persons had CVD, 15 years or more $25.1 \%$. Based on the above, there was a correlation between the work experience and the presence of pathology of the circulatory system in the examined medical workers.

The results of the survey on the attitude toward cardiovascular disorders among the surveyed health workers identified certain peculiarities. In terms of "self-assessment of health" $64 \%$ of respondents rated their health as "satisfactory," $29 \%$ - as "good," and 4\% as "bad." Only 3\% of respondents rated their level of health as "excellent." Based on "dynamic self-assessment of health level," $44 \%$ of respondents noted deterioration of their health over the last three years, while $38 \%$ was linked to their deterioration of character, the high intensity of his work. Sixty-nine percent of the surveyed health workers rated the indicator "medical activity" as average, $26.4 \%$ - as high, and $4.2 \%$ - as low. Despite the high incidence of CVD, only $15 \%$ of those surveyed were registered at the dispensary and regularly sought medical help from specialists.

\section{Conclusion}

The results of our study revealed that CVD occupies about a third of the total structure of chronic pathology among medical workers in the Northern territories. Among CVD, the most frequently registered ailments were arterial hypertension, CHD, and venous lesions of the lower extremities.

According to the results of the survey to assess the level of health in relation to the cardiovascular system, more than half of the surveyed physicians regarded it as satisfactory. At the same time, about one-third of the respondents rated their health level as excellent or good. About half of the respondents in the last three years noted a deterioration of their health, linking it to the intense medical work.

Thus, the work of medical workers, especially in extreme climatogeographic Northern conditions, can be considered as an additional risk factor for chronic diseases. The identified adverse trends in the deterioration of the medical workers' health dictate the need for the organization and implementation of preventive measures aimed at the early detection of CVD, followed by medical and recreational activities.

\section{Competing Interests}

The authors declare that they have no competing interests.

\section{References}

1. Revich BA. Determinants of public health in Arctic and Subarctic territories of Russia. Studies on Russian Economic Development. 2017;28(1):39-47.

2. Markin VV, Silin AN. [Human and Social Potential of Neo-Industrial Development of the Arctic: Sociological Analysis, Modeling, and Regulation]. Economic and Social Changes: Facts, Trends, Forecast. 2017;6:75-88. doi: 10.15838/esc.2017.6.54.[Article in Russian].

3. Dudarev AA, Odland JO. [Human health in connection with Arctic pollution - results and perspectives of international studies under the Aegis of AMAP]. Ekologiya Cheloveka [Human Ecology].2017;(9):3-14.[Article in Russian].

4. Bektasova MV, Kaptsov VA, Sheparev AA. [Occupational morbidity rate of medical workers of the Primorsky Krai (20052014)]. Gig Sanit. 2017;(3):258-60. [Article in Russian].

5. Koubassov R, Barachevsky Yu, Yuriev Yu. Hypophysisthyroid regulation features at different professional lawenforcement officer groups. International. Journal of Collaborative Research on Internal Medicine and Public Health. 2012;4(5):707-712.

6. Gatiyatullina LL. [Health status of medical professionals]. The Bulletin of Contemporary Clinical Medicine. 2016;3:6975. [Article in Russian].

7. Roslaya NA, Tulchinskaya AV. [The morbidity of medical workers according to the results of periodic medical examinations]. Annals of Ural State Medical University. 2016;(1-2):102-106. [Article in Russian].

8. Nilssen O,Kalinin A, Brenn T,Averina M,Arkhipovskij V, Brox J. Helseundersøkelsen i Arkhangelsk 2000. Tromsø, Norway; 2003. [In Norwegian and Russian]. 